Research Article

\title{
The Role of Exhaled Hydrogen Sulfide in the Diagnosis of Colorectal Adenoma
}

\author{
Nian Liu ${ }^{(D},{ }^{1}$ Yujen Tseng, ${ }^{2}$ Huilu Zhang, ${ }^{2}$ and Jian Chen ${ }^{2}{ }^{2}$ \\ ${ }^{1}$ Sunvou Medical Electronics Company, Wuxi, China \\ ${ }^{2}$ Department of Gastroenterology, Huashan Hospital of Fudan University, Shanghai, China
}

Correspondence should be addressed to Jian Chen; chen5120@126.com

Received 10 September 2021; Revised 27 October 2021; Accepted 11 November 2021; Published 30 November 2021

Academic Editor: Meng-Hao Huang

Copyright $\left({ }_{0} 2021\right.$ Nian Liu et al. This is an open access article distributed under the Creative Commons Attribution License, which permits unrestricted use, distribution, and reproduction in any medium, provided the original work is properly cited.

Purpose. Exhaled determination can detect metabolite hydrogen sulfide in the intestine. We aim to analyze the predictive value of hydrogen sulfide in the diagnosis of colorectal adenoma. Methods. We recruited seventy patients diagnosed with colorectal adenoma as the observation group and sixty-six healthy subjects as the control group. The colorectal adenoma was diagnosed by colonoscopy at the Endoscopy Center of Huashan Hospital affiliated to Fudan University from June 2018 to November 2019. Exhaled gas was collected through the nose and mouth, respectively, and hydrogen sulfide in exhaled gas was determined according to the manufacturer's instructions. Results. Receiver operating characteristic (ROC) curve was analyzed based on the exhaled data of the observation group and the control group. The ROC curve showed an area under ROC curve (AUC) 0.724 for nasal exhaled $\mathrm{H}_{2} \mathrm{~S}$, which had a diagnostic value. When nasal exhaled $\mathrm{H}_{2} \mathrm{~S}$ was $>13.3$ part per billion (ppb), the sensitivity and the specificity of predicting colorectal adenoma were $57 \%$ and $78 \%$, respectively. The exhaled $\mathrm{H}_{2} \mathrm{~S}$ of the observation group was significantly different from that of the control group. The AUC value was 0.716 as a prognostic factor of colorectal adenoma. As exhaled $\mathrm{H}_{2} \mathrm{~S}$ was $>28.8 \mathrm{ppb}$, the sensitivity and the specificity of predicting colorectal adenoma were $63 \%$ and $77 \%$, respectively. Conclusion. Exhaled and nasal $\mathrm{H}_{2} \mathrm{~S}$ determination has a predictive value for colorectal adenoma as a novel and noninvasive method. Therefore, it is worth conducting more research to analyze exhaled and nasal $\mathrm{H}_{2} \mathrm{~S}$.

\section{Introduction}

Colorectal cancer (CRC) incidence ranks the third in the world and ranks the fourth in China among malignant diseases $[1,2]$. The high incidence of CRC imposes a considerable economic and humanistic burden on the society and patients. $70 \%-90 \%$ of CRC is developed from colorectal adenoma (CRA) [3]. The synthesis and metabolism of signaling molecule- $\mathrm{H}_{2} \mathrm{~S}$ is one of the clinical manifestations that provide a theoretical basis for CRA/CRC screening and detection in the progression from CRA to CRC. There are two main sources of $\mathrm{H}_{2} \mathrm{~S}$ in the body. $\mathrm{H}_{2} \mathrm{~S}$ in the tissue and cells is synthesized by endogenous enzymes: cystathionine $\gamma$ lyase (CSE), cystathionine- $\beta$-synthase (CBS), and 3-mercaptopyruvate sulfurtransferase (3-MST). In addition, $\mathrm{H}_{2} \mathrm{~S}$ is produced from cystine by the intestinal bacteria $[4,5]$. Yamagishi et al. demonstrated that the amount of $\mathrm{H}_{2} \mathrm{~S}$ and its derivative methyl mercaptan in CRC patients is significantly higher than that of normal people in the study of digestive tract gas analysis [6]. As a gas molecule, $\mathrm{H}_{2} \mathrm{~S}$ can diffuse into the bloodstream and can be exhaled along with expiratory movements. Therefore, $\mathrm{H}_{2} \mathrm{~S}$ has the potential to become a biomarker for screening out colon tumors as a simple and noninvasive method [7].

How to screen out adenoma early and interdict it efficiently is an effective way of reducing incidence and mortality of colorectal cancer [8]. Traditional detecting methods including endoscopy, blood test, and stool DNA testing are invasive, expensive, and complicated to implement. As a result, there is an urgent need to look for a more convenient, accurate, and easy-to-carryout method for clinical practice. Gastrointestinal gas analysis is one of the optimistic methods to develop, while the gas-collecting technique is not easy in the antecedent research (anal exhaust and fecal 
fermentation), and the technique of gas analysis is complex (near edge X-ray absorption fine structure (NEXAFS) spectra and spectrophotometric determination of gas after solution preparation) $[6,9]$. Thus, a better gas-determination method is required. For the above reasons, our study determines concentration of nasal and exhaled $\mathrm{H}_{2} \mathrm{~S}$ by electrochemical sensors to predict the occurrence of CRA. We hope that exhaled $\mathrm{H}_{2} \mathrm{~S}$ determination could provide scientists and researchers some new insight into early screening and warning of CRC.

\section{Study Design and Methodology}

2.1. Study Design. 70 patients diagnosed with CRA were enrolled as the observation group and 66 healthy subjects without organic lesions were selected as the control group. The diagnosis of CRA was made via colonoscopy screening at the Endoscopy Center of Huashan Hospital Affiliated to Fudan University from June 2018 to November 2019. Inclusion criteria: (1) age $18-80$ y old, normal cognitive function, and able to complete exhaled determination; (2) not take any antibiotics or probiotics within 2 weeks before enrollment. Exclusion criteria: (1) take gastrointestinal motility drugs, acid suppressants, psychotropic drugs, immunosuppressants, intestinal microecological agents, laxatives, or antidiarrheal drugs for more than 3 days within 2 weeks of enrollment; (2) have serious systemic diseases (such as abnormal liver and kidney function and abnormal heart and lung function); (3) have a history of gastrointestinal or abdominal surgery.

This study was approved by the Ethics Committee of Huashan Hospital, ethics number: (2019), Linshen No. (471). All subjects signed an informed consent form.

2.2. Exhaled $\mathrm{H}_{2} \mathrm{~S}$ Determination. The breath test instrument is the Nanocoulomb breath analyzer DA6000 (Wuxi Sunvou Medical Electronics Co., Ltd., Wuxi, China). The measured concentration of hydrogen sulfide is one part per billion (part per billion, ppb). The instrument uses the electrochemical $\mathrm{H}_{2} \mathrm{~S}$ gas sensor. The lower limit of $\mathrm{H}_{2} \mathrm{~S}$ concentration detection is $3 \mathrm{ppb}$, detection error is $\pm 3 \mathrm{ppb}$ or $10 \%$, and detection range is $0-3000 \mathrm{ppb}$. The instrument is designed to operate in accordance with the sampling techniques in 2005 ATS/ERS [10] and the 2019 Rome Consensus [11] as well as 2017 ERS technical standards for exhaled biomarkers [12]. In order to ensure the reliability and repeatability of breath sampling, the flow rate, expiratory pressure, and duration of exhalation are set at $50 \mathrm{ml} / \mathrm{s}$, $10 \mathrm{~cm} \mathrm{H}_{2} \mathrm{O}$, and $10 \mathrm{~s}$, respectively. In order to eliminate the influence of $\mathrm{H}_{2} \mathrm{~S}$ in the environment, the subject first inhales through the $\mathrm{H}_{2} \mathrm{~S}$ filter and then exhales according to the set flow rate, expiratory pressure, and duration of exhalation. Standard gas of 50 and $200 \mathrm{ppb} \mathrm{H}_{2} \mathrm{~S} / \mathrm{N}_{2}$ provided by the manufacturer is used for calibration before the test every day in order to ensure the accuracy of the detection.

Taking into account the impact of oral $\mathrm{H}_{2} \mathrm{~S}$ on the detection of $\mathrm{H}_{2} \mathrm{~S}$ in the digestive tract, nasal exhalation is adopted to determine $\mathrm{H}_{2} \mathrm{~S}$ concentration besides oral exhalation. Results of nasal and exhaled determination are then compared and analyzed.

The detailed operation process is as follows. (1) Subject preparation: all subjects only eat rice and meat the day before the test, must fast $12 \mathrm{~h}$ before the test, and avoid workout and smoking on the day of the test. (2) Operation process: gargle before the test; during exhaled determination, the subject uses a disposable filter to wrap the lips tightly. After inhaling through the filter, hold the breath for $15 \mathrm{~s}$ and then exhale with some force. Coordinate the exhalation rhythm through animation software. The analyzer will automatically collect the end-expiratory air. During the nasal exhalation measurement, the subject uses the disposable nasal filter to align with the single test nostril and then holds breath after $15 \mathrm{~s}$ natural inhalation. As you block opposite nostril with your hand, exhale with a certain strength and coordinate the exhalation rhythm through the animation software. The analyzer will automatically collect the end-expiratory gas. After the above collection process is completed, the analyzer will automatically analyze the exhaled gas and displays the result immediately.

2.3. Statistical Method. SPSS 15.0 statistical software was used for data analysis. Normally, distributed data in the measurement data are represented by the mean \pm standard deviation, and nonnormally distributed data are represented by the median (interquartile range). $P<0.05$ is considered statistically different. $P<0.01$ is considered significantly different.

\section{Result}

3.1. Rank-Sum Test Result. The ratio of male and female is $39: 31$, and the average age is $61 \pm 13$ in the observation group. The ratio of male and female is $34: 32$, and the average age is $56 \pm 14$ in the control group. Two groups' baseline values are comparable, and there is no significant difference $(P>0.05)$.

The nasal exhalation indicator $\mathrm{H}_{2} \mathrm{~S}$ in 70 cases of colorectal adenoma and 66 cases of the control group were analyzed by the rank-sum test. The results showed that (1) the nasal exhaled $\mathrm{H}_{2} \mathrm{~S}$ in the observation group was significantly different from that in the control group $(P<0.05)$ (Table 1, Figure 1).

The exhaled indicator $\left(\mathrm{H}_{2} \mathrm{~S}\right)$ in 70 cases of colorectal adenoma and 66 cases of the control group was analyzed by the rank-sum test. The results showed that there was a significant difference in exhaled $\mathrm{H}_{2} \mathrm{~S}$ between the CRA group and Huashan control group $(P \leq 0.001)$ (Table 1 and Figure 2).

3.2. AUC Curve Analysis. Diagnostic predictive value of exhaled $\mathrm{H}_{2} \mathrm{~S}$ in colorectal adenoma: ROC curve analysis of the nasal exhaled $\mathrm{H}_{2} \mathrm{~S}$ of the two groups showed that the AUC was 0.724 , which had a diagnostic value. When the nasal exhaled $\mathrm{H}_{2} \mathrm{~S}>13.3 \mathrm{ppb}$, the sensitivity and specificity of predicting CRA were $57 \%$ and $78 \%$, respectively (Figure 3 ). ROC curve analysis of exhaled $\mathrm{H}_{2} \mathrm{~S}$ of the two groups showed 
TABLE 1: Results of exhaled determination in the observation group and control group.

\begin{tabular}{lcc}
\hline & Observation group & Control group \\
\hline Number of people (male/female) & $70(39 / 31)$ & $66(34 / 32)$ \\
Age & $61 \pm 13$ & $56 \pm 14$ \\
Nasal exhaled $\mathrm{H}_{2} \mathrm{~S}(\mathrm{ppb})$ & $19.32 \pm 15.71^{* *}$ & $10.59 \pm 4.53$ \\
Exhaled $\mathrm{H}_{2} \mathrm{~S}(\mathrm{ppb})$ & $47.47 \pm 44.95^{* *}$ & $25.00 \pm 17.94$ \\
\hline
\end{tabular}

${ }^{* *}$ Statistically significant difference between groups, $P<0.01$.

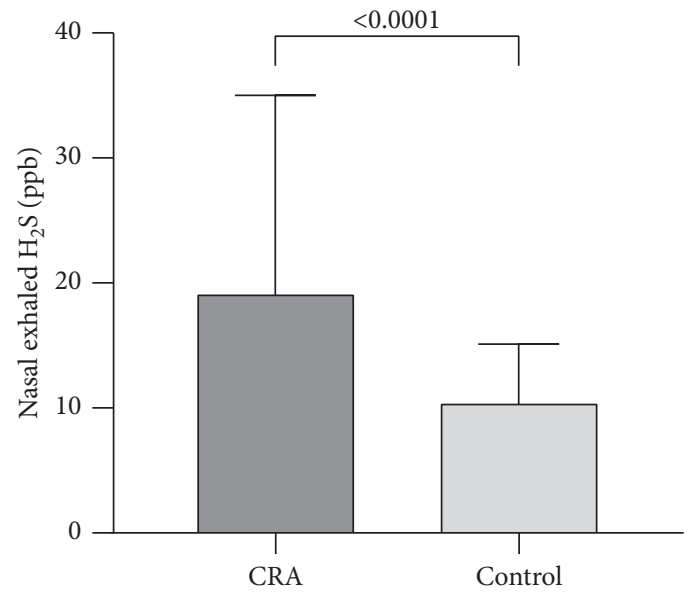

FIgURE 1: Nasal exhaled $\mathrm{H}_{2} \mathrm{~S}$ comparison between the observation group and control group.

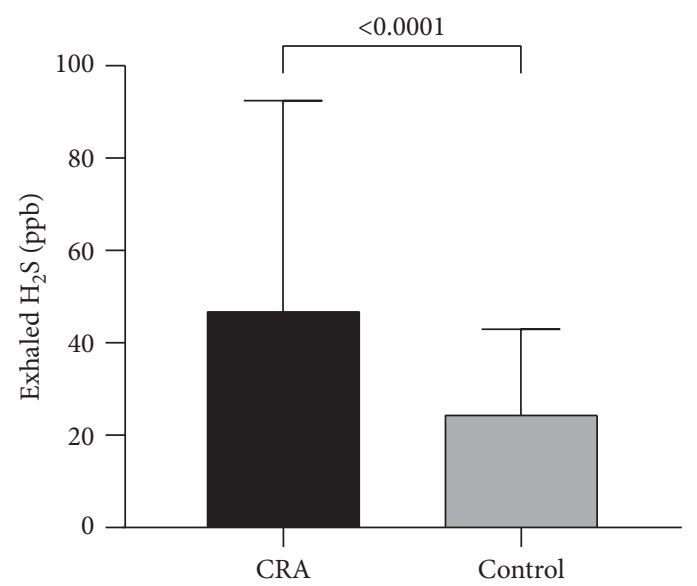

Figure 2: Exhaled $\mathrm{H}_{2} \mathrm{~S}$ comparison between two groups.

that the AUC was 0.716, which had a certain diagnostic value (Figure 3). When exhaled $\mathrm{H}_{2} \mathrm{~S}>28.8 \mathrm{ppb}$, the sensitivity for predicting CRA was $63 \%$ and the specificity was $77 \%$. Above analysis suggested that exhaled determination was better than nasal exhaled determination.

\section{Discussion}

CRA is recognized as precancerous lesion of CRC, and CRA has common pathophysiological basis as CRC. The increase of hydrogen sulfide production is one of those typical pathophysiological characters. Although, $\mathrm{H}_{2} \mathrm{~S}$ in the intestine may play a two-way role in the occurrence and development process of CRA/CRC [13], in which the overall trend of $\mathrm{H}_{2} \mathrm{~S}$ production is rising amongst people with CRA based on current research. On the one hand, the synthesis of endogenous $\mathrm{H}_{2} \mathrm{~S}$ goes up in tumor cells. On the other hand, gut microbiota metabolism shifts to prone to $\mathrm{H}_{2} \mathrm{~S}$ production during tumor genesis.

Currently, cystathionine beta-synthase CBS, cystathionine beta-synthase CSE, and 3-MST are the three main enzymes that endogenously synthesize $\mathrm{H}_{2} \mathrm{~S}$. These enzymes are all related to the occurrence and development of malignant tumors [13]. Some studies have found that CBS increases significantly in CRA/CRC [14-16]. According to Phillips et al. [16], the expression of CBS in intestinal adenoma epithelium was upregulated during the development of CRA, leading to increased $\mathrm{H}_{2} \mathrm{~S}$. CBS expression was 


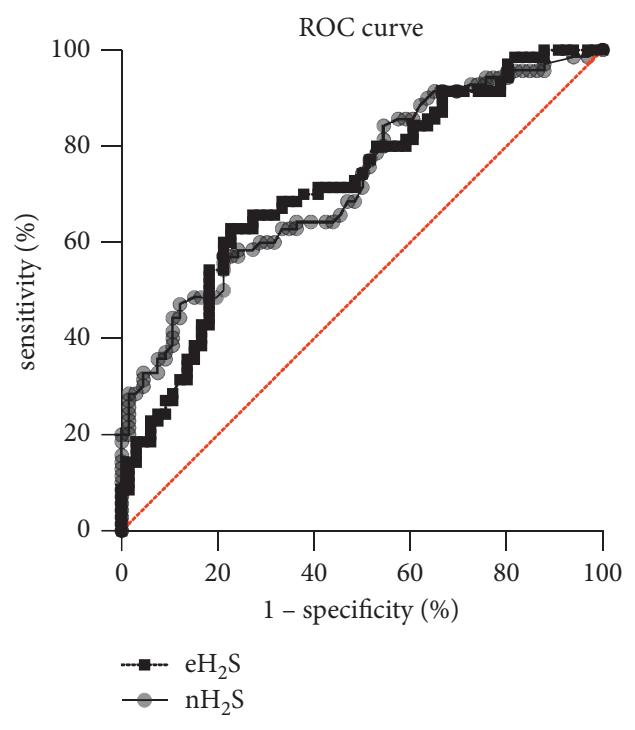

FIgURE 3: ROC curve of nasal exhaled $\mathrm{H}_{2} \mathrm{~S}\left(\mathrm{nH}_{2} \mathrm{~S}\right)$ and oral exhaled $\mathrm{H}_{2} \mathrm{~S}\left(\mathrm{eH}_{2} \mathrm{~S}\right)$.

related to the upregulation of $\mathrm{NF}-\kappa \mathrm{B}, \mathrm{K}-\mathrm{RAS}$, and $p 53$ signaling pathways as well. $\mathrm{H}_{2} \mathrm{~S}$ further promoted glycolysis of adenoma epithelium and production of ATP, thereby boosting the abnormal division and proliferation of adenoma epithelium and accelerating CRA development.

Besides endogenous synthesis, $\mathrm{H}_{2} \mathrm{~S}$ can derive from gut microbial metabolism [17]. Flannigan et al. [18] demonstrated that more than half $\mathrm{H}_{2} \mathrm{~S}$ was generated by intestinal microbiome. Shen et al. [19] also illustrated that the proportion of $\mathrm{H}_{2} \mathrm{~S}$ produced by intestinal microbiota accounted for the majority of $\mathrm{H}_{2} \mathrm{~S}$ produced by human body according to an experimental study on sterile mice and bacterial colonized mice. The $\mathrm{H}_{2} \mathrm{~S}$-producing intestinal microbiome is divided into two main types. The first type of bacteria generates $\mathrm{H}_{2} \mathrm{~S}$ by metabolizing sulfur-containing amino acids (similar to the CBS pathway of tissue cells), including Fusobacterium, Clostridium, Escherichia coli, Salmonella, Klebsiella, Streptococcus, Desulfovibrio, and some Enterobacter. Another type of bacteria produces $\mathrm{H}_{2} \mathrm{~S}$ through the sulfate metabolism, mainly Desulfovibrio [7]. Vacante [7] discovered that Biliophilus and Desulfovibrio increased significantly (control = 547) in the flora of tumor tissue and peripheral intestinal epithelium among CRA patients $(n=233)$. Moreover, the increase of Biliophilus and Desulfovibrio were obviously related to the increase of metabolite- $\mathrm{H}_{2} \mathrm{~S}$, which had the potential value for diagnosing CRA as a characteristic change. In the follow-up studies, the author found that the $\mathrm{H}_{2} \mathrm{~S}$ ion current test for colon cancer epithelium, peripheral epithelium, and distal epithelium showed a high-to-low change, which was statistically significant among CRC patients $(n=106)$. Meanwhile, some intestinal bacteria associated with $\mathrm{H}_{2} \mathrm{~S}$ change became different, such as Clostridium sclerotium, Clostridium perfringens, nematodes gingivalis, and Bacteroides fragilis [20]. These findings clearly indicated that $\mathrm{H}_{2} \mathrm{~S}$ strains derived from CRA were closely related to the progression of CRC.
After clarifying the potential value of $\mathrm{H}_{2} \mathrm{~S}$ in the diagnosis of CRA, many scholars explored the specific methods of $\mathrm{H}_{2} \mathrm{~S}$ application in CRA/CRC as well. These studies focused primarily on the detection of $\mathrm{H}_{2} \mathrm{~S}$ in human peripheral blood and feces, using methods such as methylene blue, monobromodimarane, S2-electrode ion detection, and mass spectrometry. However, methylene blue, monobromodimarane, and S2-electrode ion detection methods are susceptible to $\mathrm{pH}$ changes, so measured results may have large fluctuations. In addition, $\mathrm{H}_{2} \mathrm{~S}$ is relatively unstable and can be converted to methyl mercaptan and dimethyl disulphide in the body, which makes it difficult to draw high repeatable conclusions. Mass spectrometry is complicated and expensive and is rarely used. Therefore, a high-precision electrochemical sensor was adopted in this study to determine exhaled $\mathrm{H}_{2} \mathrm{~S}$ content among CRA patient population by the point-of-care test. The advantages of exhaled determination are as follows: (1) the $\mathrm{pH}$ and temperature in the circulating blood are relatively stable, so $\mathrm{H}_{2} \mathrm{~S}$ is less affected, and the concentration of free $\mathrm{H}_{2} \mathrm{~S}$ is relatively stable; (2) the POCT avoids $\mathrm{H}_{2} \mathrm{~S}$ being oxidized or converted to other forms; (3) holding the breath for $15 \mathrm{~s}$ ensures the full exchange of circulated gas molecules in the alveoli, which can truly reflect $\mathrm{H}_{2} \mathrm{~S}$ concentration; (4) the accuracy of the measurement is ppb level (ambient gas detection is usually ppm level), which is more sensitive to indicate the degree of $\mathrm{H}_{2} \mathrm{~S}$ change.

In this study, exhaled $\mathrm{H}_{2} \mathrm{~S}$ of the CRA group was significantly higher than that of the control group, which was statistically different. Both two sampling methods of oral exhalation (AUC 0.716) and nasal exhalation (AUC 0.724) obtained from the above results had good diagnostic value based on ROC analysis, confirming the accuracy of exhaled $\mathrm{H}_{2} \mathrm{~S}$ determination for CRA screening. Hampton [21] reported that the oral flora was associated with colonic bacterial colonization. For example, Fusobacterium nucleatum was one of the common facultative anaerobes in the oral cavity, but it was rare to be seen in the healthy people's intestine. The association between oral and colonic flora may be the key to maintaining the same trend for oral exhalation and nasal exhalation. This conclusion was in line with conclusions of previous studies $[4,6,9]$, which reflected that the overall $\mathrm{H}_{2} \mathrm{~S}$ was at a high level within the CRA population. From the realm of the physiological mechanism, exhaled $\mathrm{H}_{2} \mathrm{~S}$ is derived from the total $\mathrm{H}_{2} \mathrm{~S}$ excreted from the body through the alveolar gas exchange. A portion of total $\mathrm{H}_{2} \mathrm{~S}$ is synthesized by the CRA tissue epithelium and the rest $\mathrm{H}_{2} \mathrm{~S}$ is produced by intestinal flora. Besides, change tendency of $\mathrm{H}_{2} \mathrm{~S}$ from the two sources is determined, which is conducive to the consistent judgment of the results.

In the process of exhalation, the influence of $\mathrm{H}_{2} \mathrm{~S}$ from other sites on the results mainly included the sources of upper airway (nasal cavity) [22], lower airway (lung tissue and trachea) [23], and oral cavity [24]. How to eliminate the effect is one of the key considerations. In terms of $\mathrm{H}_{2} \mathrm{~S}$ source of upper airway (nasal cavity), the median of $\mathrm{H}_{2} \mathrm{~S}$ measured by nasal ventilation was $2 \mathrm{ppb}$. Nasal $\mathrm{H}_{2} \mathrm{~S}$ further reduced in patients with seasonal allergic rhinitis compared with the nonallergic rhinitis group according to the study of $\mathrm{Li}$ et al. 
[22]. For the $\mathrm{H}_{2} \mathrm{~S}$ source of lower airway, Zhang et al. [23, 25] demonstrated that exhaled $\mathrm{H}_{2} \mathrm{~S}$ concentration in the lower airway among some patients with either asthma or COPD increased compared with the control group. However, increase was inversely proportional to the number of eosinophils. From the perspective of inflammatory cell types and exhaled $\mathrm{H}_{2} \mathrm{~S}$ concentration, oligogranulocytic $>$ neutrophilic $>$ eosinophilic granulocytosis [25]. Even the more obvious inflammatory cell infiltration in the airway (regardless of nasal or tracheal origin) was, the less $\mathrm{H}_{2} \mathrm{~S}$ was produced. In other words, there was a negative correlation between the granulocytic infiltration and $\mathrm{H}_{2} \mathrm{~S}$ production. Therefore, based on the above research results, it was concluded that airway inflammation had little impact on the total exhaled $\mathrm{H}_{2} \mathrm{~S}$ volume. Oral cavity is the third part of $\mathrm{H}_{2} \mathrm{~S}$ source. Due to the presence of oral bacteria, Pysanenko et al. [24] found that $\mathrm{H}_{2} \mathrm{~S}$ measured orally was significantly higher than nasally, while Dryahina suggested that using nasal exhaled $\mathrm{H}_{2} \mathrm{~S}$ determination could better reflect the $\mathrm{H}_{2} \mathrm{~S}$ from the intestinal tract. Therefore, we added nasal exhaled $\mathrm{H}_{2} \mathrm{~S}$ determination on the basis of oral exhaled $\mathrm{H}_{2} \mathrm{~S}$ determination, which meant that the exhalation site was replaced with the nose. Nevertheless, the breathholding time, flow rate, and end-expiratory sampling method remained unchanged in order to eliminate the influence of the oral cavity, which further verified the predictive value of exhaled $\mathrm{H}_{2} \mathrm{~S}$ on CRA. Results revealed that the nasal exhaled $\mathrm{H}_{2} \mathrm{~S}$ (mean: $19.32 \pm 15.71 \mathrm{ppb}$ ) in the CRA group was significantly higher than that in the control group (mean: $25.00 \pm 17.94 \mathrm{ppb}$ ). In the ideal model, the nasally exhaled sampling method that excludes the influence of the oral cavity should have a better diagnostic value. Although, in this study, the ROC of the nasal exhaled sampling was slightly higher than that of the oral exhaled sampling (nasal exhaled AUC 0.724 vs. oral exhaled AUC 0.716), there is no significance between two AUCs $(P=0.86)$.

However, study design had some disadvantages. For example, fasting exhaled $\mathrm{H}_{2} \mathrm{~S}$ was a reflection of the total $\mathrm{H}_{2} \mathrm{~S}$ in the human body. Some factors may limit the diagnostic value of fasting $\mathrm{H}_{2} \mathrm{~S}$ on CRA, such as whether $\mathrm{H}_{2} \mathrm{~S}$ derived from adenoma tissue or other human tissues was affected by other factors and whether intestinal flora metabolism was affected by food, drugs, and $\mathrm{H}_{2} \mathrm{~S}$ peaks. Banik et al. [26] used fasting $\mathrm{H}_{2} \mathrm{~S}$ as a baseline value in an IBS study. The exhaled $\mathrm{H}_{2} \mathrm{~S}$ determination was performed $45 \mathrm{~min}$ after oral administration of the substrate lactulose. Subtract the baseline value from the test value as $\triangle \mathrm{H}_{2} \mathrm{~S}$ to determine whether IBS merges SIBO. This research method was to optimize the exhalation method under the condition of limiting the microbiota metabolism. How to choose a better preparation and sampling method for detecting CRA patients remained to be further explored in order to achieve an optimal diagnostic value.

In conclusion, CRA screening is essential for detecting early cancer of colon tumors. The study used exhaled $\mathrm{H}_{2} \mathrm{~S}$ determination that was a noninvasive, accurate, and innovative method. Exhaled $\mathrm{H}_{2} \mathrm{~S}$ determination provides a potential CRA inspection method and compensates shortcomings of traditional endoscopy and plasma laboratory testing, so it is worthy of further research and generalization.

\section{Data Availability}

The data used to support the findings of this study are currently under embargo while the research findings are commercialized. Requests for data, 12 months after publication of this article, will be considered by the corresponding author.

\section{Conflicts of Interest}

The authors declare that they have no conflicts of interest.

\section{Authors' Contributions}

Jian Chen conceptualized and designed the study. Nian Liu, Yuzhen Tseng, and Huilu Zhang involved in administrative support and provision of study materials or patients. Yuzhen Tseng and Huilu Zhang collected data. Nian Liu and Jian Chen analyzed and interpreted data. All authors reviewed and approved the final article.

\section{References}

[1] F. Bray, J. Ferlay, I. Soerjomataram, R. L. Siegel, L. A. Torre, and A. Jemal, "Global cancer statistics 2018: GLOBOCAN estimates of incidence and mortality worldwide for 36 cancers in 185 countries," CA: A Cancer Journal for Clinicians, vol. 68, no. 6, pp. 394-424, 2018.

[2] R. S. Zheng, K. X. Sun, S. W. Zhang et al., "Report of cancer epidemiology in China, 2015," Chinese Journal of Oncology, vol. 41, no. 1, pp. 19-28, 2019.

[3] D. R. Rudy and M. J. Zdon, "Update on colorectal cancer," American Family Physician, vol. 61, no. 6, pp. 1759-1770, 2000.

[4] F. F. Guo, T. C. Yu, J. Hong, and J. Y. Fang, "Emerging roles of hydrogen sulfide in inflammatory and neoplastic colonic diseases," Frontiers in Physiology, vol. 7, p. 156, 2016.

[5] J. Chen, Z. B. Qiu, Z. G. Luo, H. L. Zhang, and J. Liu, "Small intestinal bacterial overgrowth and low-grade systemic inflammation in 50 patients with irritable bowel syndrome," Chinese Journal of Digestion, vol. 38, no. 11, pp. 769-773, 2018.

[6] K. Yamagishi, "Generation of gaseous sulfur-containing compounds in tumour tissue and suppression of gas diffusion as an antitumour treatment," Gut, vol. 61, no. 4, pp. 554-561, 2012.

[7] M. Vacante, R. Ciuni, F. Basile, and A. Biondi, "Gut microbiota and colorectal cancer development: a closer look to the adenoma-carcinoma sequence," Biomedicines, vol. 8, no. $11,2020$.

[8] F. Amersi, M. Agustin, and C. Y. Ko, "Colorectal cancer: epidemiology, risk factors, and health services," Clinics in Colon and Rectal Surgery, vol. 18, no. 3, pp. 133-140, 2005.

[9] J. Jorgensen and P. B. Mortensen, "Hydrogen sulfide and colonic epithelial metabolism: implications for ulcerative colitis," Digestive Diseases and Sciences, vol. 46, no. 8, pp. 1722-1732, 2001.

[10] American Thoracic Society and European Respiratory Society, "ATS/ERS recommendations for standardized procedures for the online and offline measurement of exhaled lower respiratory nitric oxide and nasal nitric oxide," American Journal of 
Respiratory and Critical Care Medicine, vol. 171, no. 8, pp. 912-930, 2005.

[11] A. Gasbarrini, G. R. Corazza, G. Gasbarrini et al., "Methodology and indications of $\mathrm{H}_{2}$-breath testing in gastrointestinal diseases: the Rome consensus conference," Alimentary Pharmacology \& Therapeutics, vol. 29, no. Suppl 1, pp. 1-49, 2009.

[12] I. Horvath, P. J. Barnes, S. Loukides et al., "A European respiratory society technical standard: exhaled biomarkers in lung disease," European Respiratory Journal, vol. 49, no. 4, 2017.

[13] X. Cao, L. Ding, Z. Z. Xie, Y. Whiteman, M. Moore, and J. S. Bian, "A review of hydrogen sulfide synthesis, metabolism, and measurement: is modulation of hydrogen sulfide a novel therapeutic for cancer?" Antioxidants and Redox Signaling, vol. 31, no. 1, pp. 1-38, 2019.

[14] C. Szabo, C. Coletta, C. Chao et al., "Tumor-derived hydrogen sulfide, produced by cystathionine- $\beta$-synthase, stimulates bioenergetics, cell proliferation, and angiogenesis in colon cancer," Proceedings of the National Academy of Sciences of the United States of America, vol. 110, no. 30, pp. 12474-12479, 2013.

[15] G. Olah, K. Modis, G. Toro, M. R. Hellmich, C. Szczesny, and BandSzabo, Role of endogenous and exogenous nitric oxide, carbon monoxide and hydrogen sulfide in HCT116 colon cancer cell proliferation," Biochemical Pharmacology, vol. 149, pp. 186-204, 2018.

[16] C. M. Phillips, J. R. Zatarain, M. E. Nicholls, M. E. Porter et al., Upregulation of cystathionine- $\beta$-synthase in colonic epithelia reprograms metabolism and promotes carcinogenesis," Cancer Research, vol. 77, no. 21, pp. 5741-5754, 2017.

[17] L. Tomasova, P. Konopelski, and M. Ufnal, "Gut bacteria and hydrogen sulfide: the new old players in circulatory system homeostasis," Molecules, vol. 21, no. 11, 2016.

[18] K. L. Flannigan, T. A. Agbor, J. P. Motta et al., "Proresolution effects of hydrogen sulfide during colitis are mediated through hypoxia-inducible factor- $1 \alpha$," The FASEB Journal, vol. 29, no. 4, pp. 1591-1602, 2015.

[19] X. Shen, M. Carlstrom, S. Borniquel, C. Jädert, C. Kevil, and J. O. GandLundberg, "Microbial regulation of host hydrogen sulfide bioavailability and metabolism," Free Radical Biology \& Medicine, vol. 60, pp. 195-200, 2013.

[20] V. L. Hale, P. Jeraldo, M. Mundy et al., "Synthesis of multiomic data and community metabolic models reveals insights into the role of hydrogen sulfide in colon cancer," Methods, vol. 149 , pp. 59-68, 2018.

[21] T. Hampton, "How oral microbes exacerbate colorectal cancer," Journal of the American Medical Association, vol. 316, no. 13, p. 1349, 2016.

[22] L. Li, Y. Liu, and Q. Wang, "Levels of nasal exhaled hydrogen sulfide in the general population and allergic rhinitis patients," Journal of Clinical Laboratory Analysis, vol. 35, no. 3, Article ID e23678, 2021.

[23] J. Zhang, X. Wang, Y. Chen, and W. Yao, "Exhaled hydrogen sulfide predicts airway inflammation phenotype in COPD," Respiratory Care, vol. 60, no. 2, pp. 251-258, 2015.

[24] A. Pysanenko and P. Spanel, D. Smith, A study of sulfurcontaining compounds in mouth-and nose-exhaled breath and in the oral cavity using selected ion flow tube mass spectrometry," Journal of Breath Research, vol. 2, no. 4, p. 46004, 2008.

[25] J. Zhang, X. Wang, Y. Chen, and W. Yao, "Correlation between levels of exhaled hydrogen sulfide and airway inflammatory phenotype in patients with chronic persistent asthma," Respirology, vol. 19, no. 8, pp. 1165-1169, 2014.

[26] G. D. Banik, D. Anulekha, and S. Som, "Hydrogen sulphide in exhaled breath: a potential biomarker for small intestinal bacterial overgrowth in IBS," Journal of Breath Research, vol. 10, no. 2, p. 26010, 2016. 